\title{
Evaluasi Produk Multivitamin Baru Berdasarkan Penilaian Responden*
}

\author{
Noer Endah Islami ${ }^{1}$, Utami Dyah Syafitrii ${ }^{2 \ddagger}$, Cici Suhaeni ${ }^{3}$ \\ ${ }^{123}$ Department of Statistics, IPB University, Indonesia \\ ‡corresponding author: utamids@apps.ipb.ac.id
}

Copyright ( 2021 Noer Endah Islami, Utami Dyah Syafitri, and Cici Suhaeni. This is an open-access article distributed under the Creative Commons Attribution License, which permits unrestricted use, distribution, and reproduction in any medium, provided the original work is properly cited.

\begin{abstract}
In order to lead in the market, companies should have an innovation product. Before the innovation product launch to the market, the marketing research should be done. The goal of the research is to determine whether the new product is accepted or rejected in the market. This study was to identify the characteristics of the new product based on organoleptic point of view and performance the three type of new multivitamin products based on location and social economic classes (SEC) of respondents. MANOVA and biplot analysis were used in this research. Based on MANOVA, there were differences on the organoleptic point of view of respondents among three type of new multivitamin products. The three products had differences on the assessment of aroma, sour taste, and sour after taste. In addition with biplot analysis, it was concluded that each product had different location for sale and the target of respondents based on socio economic classes. According to respondents, product A was too sweet taste and too sour after taste in the mouth compared to others. This product was preferred by respondents who reside in South Jakarta with social economic classes (SEC) A2 and C1. Unlike product $A$, product $B$ was too hard with a bit of bitter after taste in the mouth. This product was relatively preferred by respondents in various residential with social economic classes (SEC) B. Product $C$ was strong aroma with smooth texture and more bitter taste than others. This product was preferred by respondents who reside in North Jakarta and Depok with social economic classes (SEC) A1. Overall, product B was preferred by respondents compared to other products.
\end{abstract}

Keywords: biplot analysis, MANOVA, product.

\section{Pendahuluan}

\subsection{Latar Belakang}

Perdagangan bebas di Indonesia yang semakin berkembang menyebabkan munculnya berbagai produk yang beraneka ragam di pasaran sehingga membuat tingkat persaingan antar perusahaan semakin ketat. Ketatnya persaingan menuntut

\footnotetext{
* Received: Feb 2019; Reviewed: May 2021; Published: May 2021
} 
perusahaan untuk melakukan pengembangan di perusahaan dengan mengeluarkan produk sesuai dengan inovasi yang berkesinambungan sebagai upaya perusahaan dalam melayani pasar. Pengembangan serta inovasi produk harus terus dilakukan oleh perusahaan guna mempertahankan dan meningkatkan posisi produknya di pasar, sehingga perusahaan dapat bersaing demi mempertahankan pelanggannya (Wijayanto $\mathrm{H}$ 1998).

Perusahaan XYZ yang merupakan salah satu perusahaan terkemuka di Indonesia akan mengeluarkan produk multivitamin baru. Produk tersebut terdiri dari tiga jenis yaitu produk $A, B$, dan $C$. Produk baru ini akan dibandingkan dengan produk sejenis dari perusahaan lainnya dan produk dari perusahaan $X Y Z$ sebelumnya. Perusahaan $\mathrm{XYZ}$ bekerja sama dengan salah satu perusahaan riset pemasaran di Jakarta untuk melakukan survei terhadap produk baru tersebut. Survei ini dilakukan untuk mengetahui penilaian konsumen terhadap produk baru yang akan diluncurkannya, sehingga perusahaan dapat mengevaluasi produk baru tersebut. Hasil penilaian ini dapat dijadikan informasi penting bagi perusahaan untuk memperbaiki atribut mana yang harus ditingkatkan sehingga konsumen menyukai produk perusahaan tersebut.

Setiap produk memiliki karakteristik atau atribut-atribut tertentu (Abdurrahman 2011). Atribut produk harus dapat dikendalikan dengan baik oleh perusahaan karena akan memengaruhi penilaian terhadap produk tersebut apakah dapat diterima atau tidak oleh konsumen. Pada survei ini responden diminta untuk memberikan penilaian terhadap atribut-atribut pada ketiga produk multivitamin baru dalam skala ordinal. Atribut yang dinilai terdiri dari sepuluh atribut. Sepuluh atribut ini digunakan untuk penelitian sehingga atribut harus ditransformasi menjadi skala interval menggunakan Metode Suksesif Interval (MSI) agar dapat digunakan untuk analisis lebih lanjut. Penelitian yang dilakukan (Rosiana NM 2016) menunjukkan bahwa analisis ragam peubah ganda dapat mengetahui pengaruh waktu fermentasi dan jumlah kultur campuran terhadap atribut produk yogurt. Analisis ragam peubah ganda (Multivariate Analysis of Variance atau MANOVA) merupakan teknik analisis data tentang perbedaan pengaruh beberapa variabel independen dalam bentuk kategorik dengan sekelompok variabel dependen dalam bentuk numerik. Penelitian sebelumnya yang dilakukan (Abdurrahman 2011) menunjukkan bahwa biplot dapat menggambarkan produk berdasarkan atribut dan demografi responden. Metode biplot merupakan salah satu metode analisis yang dapat digunakan untuk mengembangkan konsep produk. Metode biplot menghasilkan peta dua dimensi sehingga dapat menggambarkan ciri yang menonjol dari setiap produk menurut persepsi konsumen (Wijayanto $\mathrm{H}$ 1998). Analisis biplot diharapkan dapat memetakan dan mendeskripsikan produk pada atribut dalam dimensi dua.

\subsection{Tujuan Penelitian}

a. Mengetahui apakah ada perbedaan signifikan pada atribut-atribut yang dinilai oleh responden antar ketiga jenis produk multivitamin baru.

b. Mengetahui performa produk tersebut secara keseluruhan berdasarkan penilaian atribut dan karakteristik responden.

\section{Tinjauan Pustaka}

2.1 Metode Suksesif Interval (MSI) 
Metode Suksesif Interval (MSI) merupakan sebuah metode untuk mentransformasi data dari skala ordinal menjadi interval (Hays (1976)) dalam (Waryanto B (2006)). Pada penelitian di bidang ilmu sosial biasa digunakan data kualitatif (nominal dan ordinal) sebagai refleksi dari konsep yang sifatnya tidak bisa diukur secara langsung. Konsep tersebut dituangkan dalam kuesioner sehingga dapat ditanyakan terhadap responden. Pada umumnya jawaban responden yang diukur dengan menggunakan skala ordinal diadakan skoring yakni pemberian nilai numerik 1, 2, 3, 4, dan 5, setiap skor yang diperoleh akan memiliki tingkat pengukuran ordinal. Nilai numerikal tersebut dianggap sebagai objek dan selanjutnya melalui proses transformasi ditempatkan ke dalam interval. Penggunaan alat analisis umumnya ditentukan skala minimal dari data yang dibutuhkan. Pada penelitian di bidang ilmu sosial banyak menggunakan skala ordinal, sementara persyaratan alat analisis membutuhkan data dengan skala minimal adalah skala interval sehingga data perlu ditransformasikan dari skala ordinal ke interval.

Langkah-langkah dalam Metode Suksesif Interval (MSI) (Sarwono J 2014) yaitu:

a. Menghitung frekuensi dari setiap data kategori (F). Frekuensi merupakan banyaknya tanggapan responden dalam memilih poin di setiap kategori yang ada.

b. Menghitung proporsi berdasarkan frekuensi dari setiap data kategori (P). Proporsi dihitung dengan membagi setiap frekuensi dengan jumlah responden.

c. Menghitung proporsi kumulatif (PK). Proporsi kumulatif dihitung dengan menjumlahkan proporsi secara berurutan untuk setiap nilai.

d. Menghitung nilai $z$ untuk setiap proporsi kumulatif. Nilai $z$ diperoleh dari tabel distribusi normal baku, dengan asumsi bahwa proporsi kumulatif dianggap mengikuti distribusi normal baku.

e. Menghitung nilai densitas fungsi z. Nilai densitas dihitung dengan menggunakan rumus sebagai berikut:

$$
f(z)=\frac{1}{\sqrt{2 \pi}} \exp \left(-\frac{1}{2} z^{2}\right)
$$

f. Menghitung scale value (nilai skala) untuk setiap kategori. Menghitung scale value (nilai skala) dengan rumus:

$\mathrm{a}=$ densitas $\mathrm{bb}$ - densitas ba

$$
\text { Nilai Skala }(S V)=\frac{a}{b}
$$

$\mathrm{b}=$ proporsi kumulatif ba - proporsi kumulatif

$*$ ba $=$ batas atas, $\mathrm{bb}=$ batas bawah

g. Menentukan nilai transformasi (nilai skala interval). Menghitung nilai transformasi (nilai skala interval) digunakan rumus:

$$
\text { transformasi }=\text { skala }+\mid \text { skala minimum } \mid+1
$$

\subsection{Analisis Ragam Peubah Ganda (Multivariate Analysis of Variance atau MANOVA)}

Suatu metode untuk menguraikan keragaman total data menjadi komponenkomponen yang mengukur berbagai sumber keragaman adalah metode analisis ragam (Walpole (1995)). Analisis ragam peubah ganda (Multivariate Analysis of Variance atau MANOVA) adalah perluasan dari konsep teknik analisis ragam (Analysis 
of Variance atau ANOVA). Metode MANOVA merupakan salah satu metode statistika yang digunakan untuk mengkaji pengaruh dari berbagai faktor yang dicobakan terhadap peubah respon ganda (lebih dari satu peubah respon). Metode MANOVA mempertimbangkan adanya ketergantungan antar peubah respon sehingga baik digunakan untuk pengkajian pengaruh dari berbagai faktor terhadap lebih dari satu respon (Matjjik AA (2011)). Analisis ragam peubah ganda satu arah merupakan pengembangan dari analisis ragam satu peubah satu arah. Pada percobaan yang ingin mengkaji pengaruh dari t buah perlakuan terhadap $\mathrm{p}$ buah respon secara serempak, dimana $p>1$, maka penelitian itu dapat dianalisis dengan analisis ragam peubah ganda satu arah. Model linier yang dapat dituliskan dalam percobaan ini adalah:

$$
y_{i j k}=\mu_{k}+\tau_{i k}+e_{i j k}
$$

dimana $i=1,2, \ldots, t ; j=1,2, \ldots, r ; k=1,2, \ldots, p$;

dengan:

$y_{i j k}=$ nilai pengamatan dari respon ke-k dan ulangan ke-j yang memperoleh perlakuan ke-i

$\mu_{k} \quad=$ nilai rataan umum dari respon ke-k.

$\tau_{i k} \quad=$ pengaruh perlakuan ke-i terhadap respon ke-k.

$e_{i j k}=$ pengaruh galat yang timbul pada respon ke-k dari ulangan ke-j dan perlakuan ke-i.

dengan $\sum_{i=1}^{a} n_{i} \tau_{i}=0$ dan $e_{i j k}$ merupakan vector galat yang bersifat bebas dan menyebar normal ganda dengan vektor nilai rata-rata 0 dan matriks peragam $\Sigma\left(\varepsilon_{i j k} N p(0, \Sigma)\right)$.

Pengujian untuk mengetahui adanya perbedaan pengaruh perlakuan terhadap beberapa variabel respon dapat dilakukan dengan uji Wilks Lambda. Bentuk hipotesis yang diuji adalah sebagai berikut:

$H_{0}: \mu_{1}=\mu_{2}=\cdots=\mu_{i}$ (tidak ada satu kelompok yang memberikan pengaruh berbeda terhadap variabel respon).

$H_{1}: \mu_{i} \neq \mu_{j}, i=1,2, \ldots, t ; j=1,2, \ldots, r$; (paling sedikit ada satu kelompok yang memberikan pengaruh berbeda terhadap variabel respon).

Statistik uji untuk pengujian ini yaitu:

$$
\Lambda=\frac{|W|}{|B+W|}
$$

\subsection{Asumsi Analisis Ragam Peubah Ganda (Multivariate Analysis of Variance atau MANOVA)}

\section{Asumsi Homogenitas Matriks Ragam-Koragam}

Hipotesis yang digunakan untuk menguji asumsi homogenitas matriks ragamkoragam adalah:

$H_{0}: \Sigma_{1}=\Sigma_{2}=\cdots=\Sigma_{i}$ (matriks ragam-koragam homogen). 
$H_{1}$ : ada paling sedikit satu $\Sigma_{i} \neq \Sigma_{j}$ untuk $i=j=1,2, \ldots, k$ dan $i \neq j$ (matriks ragam-koragam tidak homogen).

Pengujian homogenitas matriks ragam-koragam dapat dilakukan dengan uji Boxs $M$ dengan rumusan:

$M=\sum_{i=1}^{k}\left(n_{i}\right) \ln |S|-\sum_{i=1}^{k}\left(n_{i}\right) \ln \left|S_{i}\right| \quad$ dengan $S=\sum_{i=1}^{k} \frac{n_{i} S_{i}}{\sum n_{i}}$ adalah matriks dugaan ragam- koragam. Menurut Morrison (1967) dalam Saepudin (2005), jika dari masing-masing populasi diambil sampel acak berukuran $\mathrm{n}$ dan saling bebas maka untuk $\Sigma_{i}$ diduga oleh $S_{i}$ sedangkan untuk $\Sigma$ diduga oleh $S$ serta untuk $n_{i}$ adalah derajat bebas. Boxes merupakan faktor skala $C^{-1}$ yang mempunyai rumus:

$$
C^{-1}=1-\frac{2 p^{2}+3 p-1}{6(p+1)(k-1)}\left(\sum_{i=1}^{k} \frac{1}{\left(n_{i}\right)}-\frac{1}{\sum_{i=1}^{k}\left(n_{i}\right)}\right)
$$

dengan $p=$ banyaknya peubah dan $n_{i}=N_{i}-1, N_{i}=$ banyaknya pengamatan pada masing-masing peubah bebas. Ho diterima jika $M C^{-1} \leq \chi_{\left(\frac{1}{2}(k-1) p(p+1) \alpha\right)}^{2}$.

\section{Asumsi Normal Ganda}

Pemeriksaan penyebaran normal ganda dapat dilihat dengan menggunakan plot jarak mahalanobis terhadap khi kuadrat. Jika $x_{1}, x_{2}, \ldots, x_{p}$ menyebar normal ganda dengan parameter $\mu$ dan $\Sigma$ serta mempunyai fungsi kepekatan peluang yaitu:

$$
f\left(x_{1}, x_{2}, \ldots, x_{p}\right)=\frac{1}{(2 \pi)^{p / 2}|\Sigma|^{1 / 2}} e^{-\frac{1}{2}(X-\mu) \Sigma^{-1}(X-\mu)}
$$

Pengujian hipotesis asumsi normal ganda sebagai berikut:

$H_{0}$ : Data menyebar normal ganda.

$H_{0}$ : Data tidak menyebar normal ganda.

Nilai $\mu$ dan $\Sigma$ diduga dengan nilai $\underline{x}$ dan $S^{-1}$ untuk $(X-\mu)^{\prime} \Sigma^{-1}(X-\mu)$. Pemeriksaan asumsi ini dilakukan dengan cara menghitung jarak mahalanobis dari setiap pengamatan $d_{i}^{2}$ mengikuti sebaran khi-kuadrat dengan rumus:

$$
d_{i}^{2}=\left(x_{i}-\underline{x}\right)^{\prime} S^{-1}\left(x_{i}-\underline{x}\right) ; i=1,2, \ldots, n
$$

Dengan $S^{-1}$ adalah matriks kebalikan peragam. Statistik $d_{1}^{2} \leq d_{2}^{2} \leq \cdots \leq d_{n}^{2}$ kemudian diplotkan dengan kuantil khi-kuadrat $\chi_{p, \alpha((i-0.5) / n)}^{2}$. Secara visual, jika plot cenderung membentuk garis lurus maka dapat dikatakan bahwa data menyebar normal ganda.

\subsection{Analisis Biplot}


Biplot adalah salah satu upaya menggambarkan data-data yang ada pada tabel ringkasan dalam grafik berdimensi dua. Informasi yang diberikan oleh biplot mencakup objek dan peubah dalam satu gambar atau peta sehingga perilaku data mudah dilihat dan diinterpretasikan (Sartono et al. dalam Mattjik dan Sumertajaya 2011). Peta tersebut dapat disajikan secara visual guna menyajikan secara simultan $n$ objek pengamatan dan p peubah dalam ruang bidang dimensi dua, sehingga ciri-ciri peubah dan objek pengamatan serta posisi relatif antar objek pengamatan dengan peubah dapat dianalisis (Jolliffe (2002)).

Suatu matriks data $\mathbf{X}$ berpangkat $r$ dan berukuran $n x p$ dengan $n$ adalah banyaknya objek pengamatan dan $p$ adalah banyaknya peubah yang terkoreksi terhadap nilai rata-ratanya. Matriks $\mathbf{X}$ tersebut diuraikan berdasarkan konsep SVD (Singular Value Decomposition) sehingga dapat dituliskan menjadi (Wijayanto $\mathrm{H}$ (1998)).

$$
X=U L A^{\prime}
$$

dengan $\mathbf{U}$ dan $\mathbf{A}$ merupakan matriks yang masing- masing berukuran $n x r$ dan $p x r$ sehingga $U^{\prime} U=A^{\prime} A=I_{r}$

$\mathbf{L}$ adalah matriks diagonal berukuran $r x r$ dengan unsur-unsur diagonal utamanya adalah akar-akar kuadrat dari akar ciri yang tidak nol dari matriks $X^{\prime} X$ sehingga $\lambda_{1} \geq$ $\lambda_{2} \geq \ldots \geq \lambda_{r}$. Lajur- lajur matriks A tidak lain adalah vektor-vektor ciri dari matriks $X^{\prime} X$, sedangkan lajur-lajur matriks $\mathbf{U}$ dapat dihitung melalui persamaan:

$$
\begin{gathered}
u i=\frac{1}{\sqrt{\lambda_{i}}} \times a_{i}, \quad i=1,2, \ldots, r \\
A=\left[a_{1} a_{2} \ldots a_{r}\right]
\end{gathered}
$$

dengan $\lambda_{i}$ adalah akar ciri ke-i dari matriks $X^{\prime} X$ dan $a_{i}$ adalah lajur ke-i matriks $\mathbf{A}$. Penguraian melalui konsep SVD (Singular Value Decomposition) telah diperoleh sehingga matriks $\mathbf{X}$ dapat difaktorkan dalam bentuk:

$$
X=U L^{\alpha} L^{1-\alpha} A^{\prime}=G H^{\prime}
$$

dengan $G=U L^{\alpha}$ dan $H^{\prime}=L^{1-\alpha} A^{\prime}$ yang masing-masing berukuran $n x r$ dan $p x r$.

Menurut Jolliffe (2002) unsur ke-(i,j) matriks $\mathbf{X}$ dapat dituliskan sebagai berikut:

$$
X_{i j}=g_{i}^{\prime} h_{j}
$$

dengan $i=1,2, \ldots, n$ dan $j=1,2, \ldots, p . g_{i}$ dan $h_{j}$ masing-masing merupakan baris-baris dari matriks $\mathbf{G}$ dan $\mathbf{H}$. Jika matriks $\mathbf{X}$ berpangkat dua maka vektor pengaruh baris $g_{i}$ dan vektor pengaruh lajur $h_{j}$ dapat digambarkan dalam ruang berdimensi dua.

Biplot berupaya membuat gambar di ruang berdimensi banyak menjadi gambar di ruang dimensi dua dengan cara mereduksikan dimensi. Pereduksian ini mengakibatkan penurunan informasi yang terkandung dalam biplot sehingga nilai dimensi yang lebih besar dari 70\% dianggap sudah dapat memberikan informasi dari keseluruhan data. Beberapa informasi yang dapat diperoleh dari tampilan biplot adalah (Mattjik dan Sumertajaya 2011): 
a. Kedekatan antar objek yang diamati.

Dua objek yang memiliki karakteristik yang sama akan digambarkan sebagai dua titik yang posisinya berdekatan.

b. Keragaman peubah.

Peubah yang memiliki nilai keragaman kecil digambarkan sebagai vektor pendek, sedangkan peubah yang memiliki nilai keragaman besar digambarkan sebagai vektor panjang.

c. Hubungan antar peubah.

Pada biplot, peubah akan digambarkan sebagai garis berarah. Jika sudut antara dua peubah kurang dari 90 o maka hubungan antar peubah tersebut bernilai positif, demikian pula sebaliknya. Semakin kecil nilai sudut antara dua peubah maka semakin kuat hubungan antara dua peubah tersebut.

d. Nilai peubah pada suatu objek.

Karakteristik suatu objek bisa disimpulkan dari posisi relatifnya yang paling dekat dengan suatu peubah. Objek yang memiliki nilai tinggi pada suatu karakteristik, akan digambarkan searah dengan vektor peubah yang bersangkutan, demikian pula sebaliknya.

\section{Metodologi}

\subsection{Data}

Data yang digunakan dalam penelitian ini merupakan data sekunder dari hasil survei yang dilakukan oleh salah satu perusahaan riset pemasaran di Jakarta yang bekerjasama dengan perusahaan XYZ. Survei ini dilakukan pada bulan Mei tahun 2014 di daerah Jakarta, Bogor, Depok, Tangerang, dan Bekasi. Tujuan survei ini adalah untuk mengetahui preferensi dan tingkat penerimaan pasar terhadap produk baru dengan sasaran utama yaitu anak-anak di usia TK dan Sekolah Dasar. Metode penarikan contoh yang digunakan adalah metode penarikan contoh acak tidak berpeluang yaitu penarikan contoh dengan tujuan tertentu (purposive sampling). Responden yang disurvei merupakan ibu rumah tangga dengan jumlah 110 responden. Kriteria responden terdiri atas:

1. Responden harus bertempat tinggal di daerah Jakarta, Bogor, Depok, Tangerang, dan Bekasi.

2. Ibu rumah tangga yang memiliki anak berusia 7-8 tahun atau bersekolah kelas 23 Sekolah Dasar.

3. Pengonsumsi produk dari perusahaan yang sama dalam enam bulan terakhir.

4. Berada dalam kelas sosial ekonomi (SEC) terdiri dari kelas $A 1$, kelas $A 2$, kelas $B$, dan kelas C1. Kelas sosial ekonomi (SEC) tersebut ditentukan berdasarkan besarnya pengeluaran rumah tangga per bulan.

Pada survei ini responden diminta untuk memberikan penilaian terhadap atributatribut pada produk multivitamin baru dalam skala ordinal. Skala ini terdiri dari skala 1 dengan kategori yang paling rendah hingga skala 3 dengan kategori tertinggi. Produk multivitamin baru yang dinilai terdiri dari tiga jenis yaitu produk $A, B$, dan $C$. Teknik 
pengumpulan data yang digunakan adalah Central Location Test (CLT). Central Location Test (CLT) merupakan suatu teknik penelitian yang melibatkan responden, dimana responden diundang ke suatu tempat yang ditentukan, baik melalui pemberitahuan atau tanpa pemberitahuan sebelumnya untuk mengevaluasi produkproduk yang diujikan. Metode evaluasi produk yang digunakan adalah sequential monadic testing. Sequential monadic testing merupakan metode evaluasi produk yang melibatkan responden untuk mengevaluasi semua produk dengan cara dirotasi satu demi satu.

Pada penelitian ini data yang digunakan merupakan data berskala ordinal sehingga data ini perlu ditransformasi menjadi skala interval menggunakan Metode Suksesif Interval (MSI) agar dapat digunakan untuk analisis lebih lanjut. Sepuluh atribut yang telah ditransformasi digunakan sebagai peubah respon sedangkan ketiga jenis produk multivitamin baru yang berskala nominal digunakan sebagai kelompok. Produk $A$ dianggap sebagai kelompok satu, produk $B$ sebagai kelompok 2 , dan produk $C$ sebagai kelompok 3. Karakteristik responden yang terdiri dari tempat tinggal (Jakarta Barat, Jakarta Timur, Jakarta Pusat, Jakarta Utara, Jakarta Selatan, Bogor, Bekasi, Depok, dan Tangerang) dan kelas sosial ekonomi (SEC A1, SEC A2, SEC B, dan SEC C1) juga digunakan pada penelitian ini.

Tabel 1 Daftar Atribut yang Dinilai

\begin{tabular}{llllll}
\hline Atribut & & Kategori & Atribut & & Kategori \\
\hline Warna & 1 & Terlalu gelap & Aroma & 1 & Kurang kuat \\
& 2 & Pas & & 2 & Pas \\
\multirow{4}{*}{ Tekstur } & 3 & Terlalu cerah & & 3 & Terlalu kuat \\
& 1 & Terlalu kasar & Kekerasan & 1 & Terlalu kasar \\
& 2 & Pas & & 2 & Pas \\
Rasa manis & 3 & Terlalu halus & & 3 & Terlalu lembek \\
& 1 & Kurang manis & Rasa manis & 1 & Kurang manis \\
& 2 & Pas & yang tersisa & 2 & Pas \\
Rasa asam & 3 & Terlalu manis & & 3 & Terlalu manis \\
& 1 & Kurang asam & Rasa asam & 1 & Kurang asam \\
& 2 & Pas & yang tersisa & 2 & Pas \\
\multirow{4}{*}{ Rasa pahit } & 3 & Terlalu asam & & 3 & Terlalu asam \\
& 1 & Kurang pahit & Rasa pahit & 1 & Kurang pahit \\
& 2 & Pas & yang tersisa & 2 & Pas \\
& 3 & Terlalu pahit & & 3 & Terlalu pahit \\
\hline
\end{tabular}

\subsection{Metode Analisis Data}

Tahapan-tahapan analisis yang dilakukan dalam penelitian ini adalah sebagai berikut:

1) Melakukan analisis statistika deskriptif untuk menggambarkan secara umum karakteristik responden dan atribut-atribut produk multivitamin baru yang dinilai oleh responden. 
2) Melakukan transformasi data dengan menggunakan Metode Suksesif Interval (MSI) agar data dapat dianalisis menggunakan analisis ragam peubah ganda.

3) Melakukan analisis ragam peubah ganda (Multivariate Analysis of Variance atau MANOVA) untuk mengetahui apakah ada perbedaan pada atribut-atribut yang dinilai oleh responden antar ketiga jenis produk multivitamin baru.

4) Melakukan pengujian asumsi analisis ragam peubah ganda.

5) Melakukan analisis biplot untuk mengetahui performa produk multivitamin baru secara keseluruhan dengan menyajikan segugus objek produk baru terhadap peubah atribut dan karakteristik responden (tempat tinggal dan kelas sosial ekonomi (SEC)) kemudian menginterpretasikan pada biplot yang dihasilkan.

\section{Hasil dan Pembahasan}

\subsection{Analisis Deskriptif}

Gambar 1 menunjukkan rincian karakteristik responden berdasarkan tempat tinggal. Sebanyak $11.8 \%$ dari 110 responden bertempat tinggal di daerah Jakarta Pusat, Jakarta Timur, dan Depok. Sebanyak 10.9\% dari 110 responden responden bertempat tinggal di daerah Jakarta Barat, Jakarta Utara, Bogor, Tangerang, dan Bekasi, sisanya bertempat tinggal di daerah Jakarta Selatan.

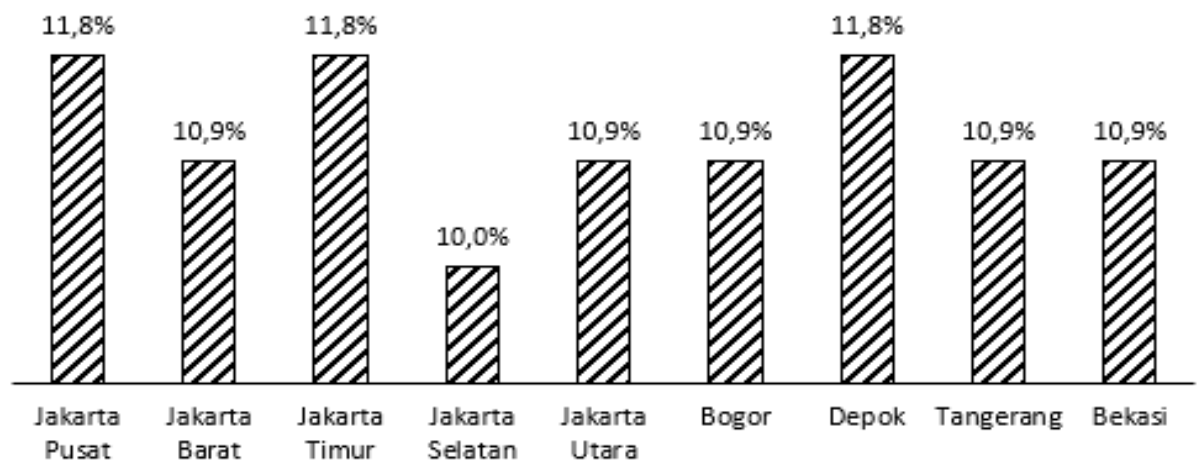

Gambar 1. Karakteristik responden berdasarkan tempat tinggal

Kelas sosial ekonomi (SEC) responden ditentukan berdasarkan besarnya pengeluaran rumah tangga per bulan. Penentuan kriteria ini menjadikan kelas sosial ekonomi (SEC) terbagi menjadi empat kelas. Gambar 2 yang merupakan rincian karakteristik berdasarkan kelas sosial ekonomi (SEC) responden terlihat bahwa sebagian besar responden berada pada kelas sosial ekonomi (SEC) B dengan besar pengeluaran rumah tangga per bulan antara Rp 3.501 .000 sampai $R p$ 4.500.000. Sebanyak 32.7\% dari 110 responden berada pada kelas sosial ekonomi (SEC) A1 dengan besar pengeluaran rumah tangga lebih dari Rp 4.500 .000 per bulan. Sebanyak $11.8 \%$ dari 110 responden berada pada kelas sosial ekonomi (SEC) A2 dengan besar pengeluaran rumah tangga per bulan antara Rp 2.501.000 sampai Rp 3.500.000, dan sisanya berada pada kelas sosial ekonomi (SEC) $\mathrm{C} 1$ dengan besar pengeluaran rumah tangga kurang dari Rp 2.500.000 per bulan.

Pada Gambar 3 merupakan rincian penilaian responden atribut warna pada ketiga produk multivitamin baru. Sebagian besar responden menilai bahwa ketiga produk multivitamin baru tersebut memiliki warna yang pas. Hal ini terlihat dari banyaknya 
responden yang menilai atribut warna pada kategori pas memiliki persentase $50 \%$ pada produk A, $49.1 \%$ pada produk B, dan $46.4 \%$ pada produk C. Sebagian besar responden menilai bahwa ketiga produk multivitamin baru tersebut memiliki tekstur, rasa manis, rasa asam, rasa pahit, aroma, kekerasan, rasa manis yang tersisa, rasa asam yang tersisa, dan rasa pahit yang tersisa yang pas. Hal ini dikarenakan banyaknya responden yang menilai atribut-atribut tersebut pada kategori pas hampir semua memiliki persentase lebih dari $50 \%$.

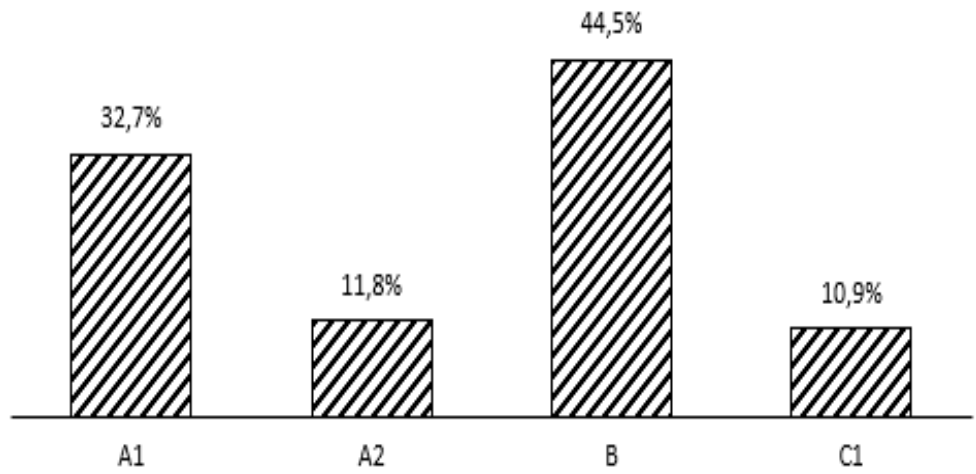

Gambar 2. Karakteristik responden berdasarkan kelas sosial ekonomi (SEC)

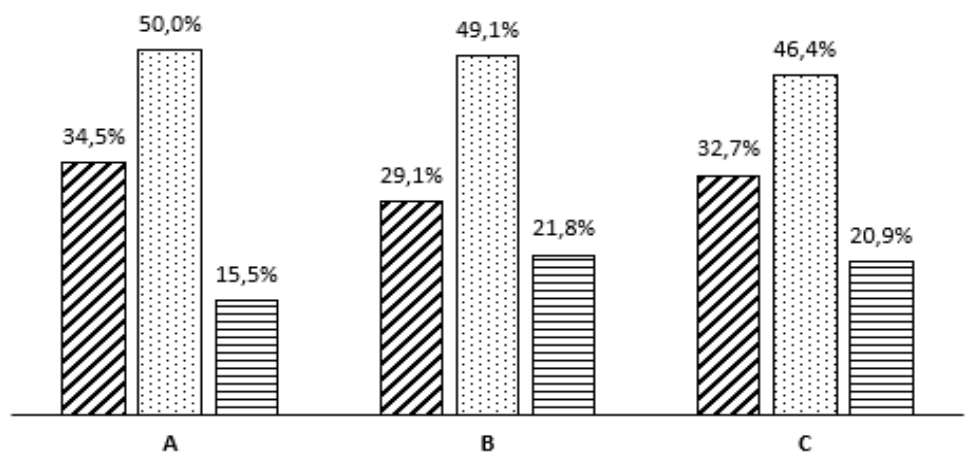

Gambar 3. Penilaian responden terhadap atribut warna pada ketiga produk multivitamin baru (terlalu gelap, pas, terlalu cerah)

\subsection{Analisis Ragam Peubah Ganda (Multivariate Analysis of Variance atau MANOVA)}

Pengujian analisis ragam peubah ganda (Multivariate Analysis of Variance atau MANOVA) menggunakan metode uji Wilks Lambda dengan taraf signifikansi $\alpha=0.05$ menghasilkan nilai peluang nyata sebesar 0.000 . Nilai ini lebih kecil dari taraf signifikansi a yang digunakan sehingga dapat disimpulkan bahwa antar ketiga jenis produk multivitamin baru memiliki perbedaan signifikan dengan taraf nyata $5 \%$ dari segi atribut organoleptik. Tabel 2 merupakan tabel analisis ragam pada masing-masing atribut-atribut yang dinilai oleh responden antar ketiga jenis produk multivitamin baru. Pada Tabel 2 terdapat tiga atribut yang memiliki nilai peluang nyata lebih kecil dari taraf a yaitu atribut aroma, rasa asam, dan rasa asam yang tersisa. Hal ini dapat disimpulkan bahwa ada perbedaan signifikan pada penilaian aroma, rasa asam, dan rasa asam yang tersisa oleh responden antar ketiga produk multivitamin baru, sedangkan pada atribut- atribut produk baru lainnya tidak memiliki perbedaan signifikan antar ketiga jenis produk multivitamin baru. 
Tabel 2 Analisis Ragam pada Masing-Masing Atribut

\begin{tabular}{lrl}
\hline Respon & F-Hitung & P \\
\hline Warna & 0.439 & 0.645 \\
Tekstur & 0.526 & 0.592 \\
Rasa manis & 1.379 & 0.253 \\
Rasa asam & $\mathbf{3 . 4 1 3}$ & $\mathbf{0 . 0 3 4}$ \\
Rasa pahit & 1.300 & 0.274 \\
Aroma & $\mathbf{1 1 . 2 7 6}$ & $\mathbf{0 . 0 0 0}$ \\
Kekerasan & 0.159 & 0.853 \\
Rasa manis yang tersisa & 1.202 & 0.302 \\
Rasa asam yang tersisa & $\mathbf{5 . 1 8 9}$ & $\mathbf{0 . 0 0 6}$ \\
Rasa pahit yang tersisa & 0.040 & 0.961 \\
\hline "signifikan pada $\alpha=0.05$ & &
\end{tabular}

\section{a. Asumsi Homogenitas Matriks Ragam-Koragam}

Hasil metode uji Box's $M$ terhadap kehomogenan matriks ragam-koragam dengan nilai Fhitung sebesar 1.107 dan nilai peluang nyata sebesar 0.209 . Hal ini menunjukkan nilai peluang nyata memiliki nilai lebih besar dari nilai taraf signifikansi a yang digunakan yaitu 0.05 . Pada hasil yang diperoleh dapat disimpulkan bahwa matriks ragam-koragam homogen.

\section{b. Asumsi Normal Ganda}

Pemeriksaan penyebaran normal ganda dapat dilihat dengan menggunakan plot jarak mahalanobis terhadap khi-kuadrat. Gambar 4 merupakan plot jarak mahalanobis terhadap khi-kuadrat berdasarkan data yang digunakan. Sebaran titik-titik pada plot tersebut cenderung membentuk garis lurus sehingga dapat dikatakan asumsi ini terpenuhi.

\subsection{Analisis Biplot terhadap Peubah Atribut}

Analisis biplot yang dilakukan pada ketiga produk multivitamin baru terhadap peubah atribut memberikan informasi keragaman sebesar $100 \%$ dengan $66.4 \%$ pada sumbu 1 dan $33.6 \%$ pada sumbu 2. Nilai ini menunjukkan bahwa interpretasi biplot yang dihasilkan sudah dapat menerangkan dengan baik hubungan antara produk multivitamin baru terhadap atribut-atributnya. Pada Gambar 5 terlihat peubah atribut rasa manis memiliki panjang vektor yang relatif panjang. Hal ini menunjukkan bahwa atribut tersebut memiliki tingkat keragaman yang tinggi sehingga dapat diinterpretasikan bahwa penilaian responden terhadap atribut rasa manis beragam antar ketiga produk multivitamin baru tersebut. Tingkat keragaman dapat diukur melalui simpangan baku. Nilai-nilai simpangan baku dari setiap peubah atribut yang disajikan pada Tabel 3 memiliki perbedaan sangat kecil antar setiap peubah atribut sehingga panjang vektor yang disajikan pada biplot memiliki panjang yang hampir sama untuk setiap peubah atribut.

Gambar 5 memberikan gambaran posisi objek dan vektor peubah dalam biplot. Produk $\mathrm{A}$ cenderung dekat dengan atribut rasa manis dan rasa asam yang tersisa. 
Produk A dipersepsikan oleh responden sebagai produk yang memiliki rasa yang lebih manis serta lebih asam yang tersisa di dalam mulut dibandingkan produk lainnya. Produk B dipersepsikan sebagai produk yang terlalu keras dengan rasa yang tersisa di dalam mulut kurang pahit menurut responden. Produk $\mathrm{C}$ dipersepsikan oleh responden sebagai produk yang memiliki aroma yang kuat dengan kehalusan tekstur relatif tinggi serta rasa yang lebih pahit dari produk lainnya.

\begin{tabular}{lc} 
Tabel 3 Simpangan Baku dari Setiap Peubah Atribut \\
\hline Atribut & $\begin{array}{c}\text { Simpangan } \\
\text { baku }\end{array}$ \\
\hline Warna & 0.059 \\
Tekstur & 0.055 \\
Rasa manis & 0.083 \\
Rasa asam & 0.029 \\
Rasa pahit & 0.042 \\
Aroma & 0.068 \\
Kekerasan & 0.005 \\
Rasa manis yang tersisa & 0.065 \\
Rasa asam yang tersisa & 0.036 \\
Rasa pahit yang tersisa & 0.068 \\
\hline
\end{tabular}

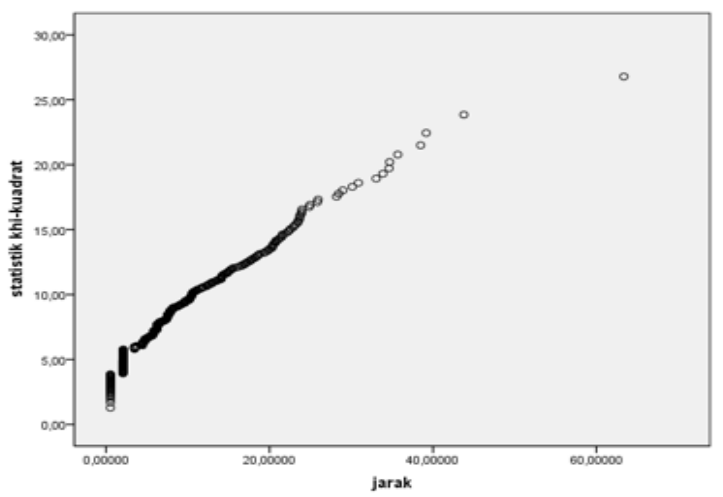

Gambar 4. Plot jarak mahalanobis dan quantil khi-kuadrat 


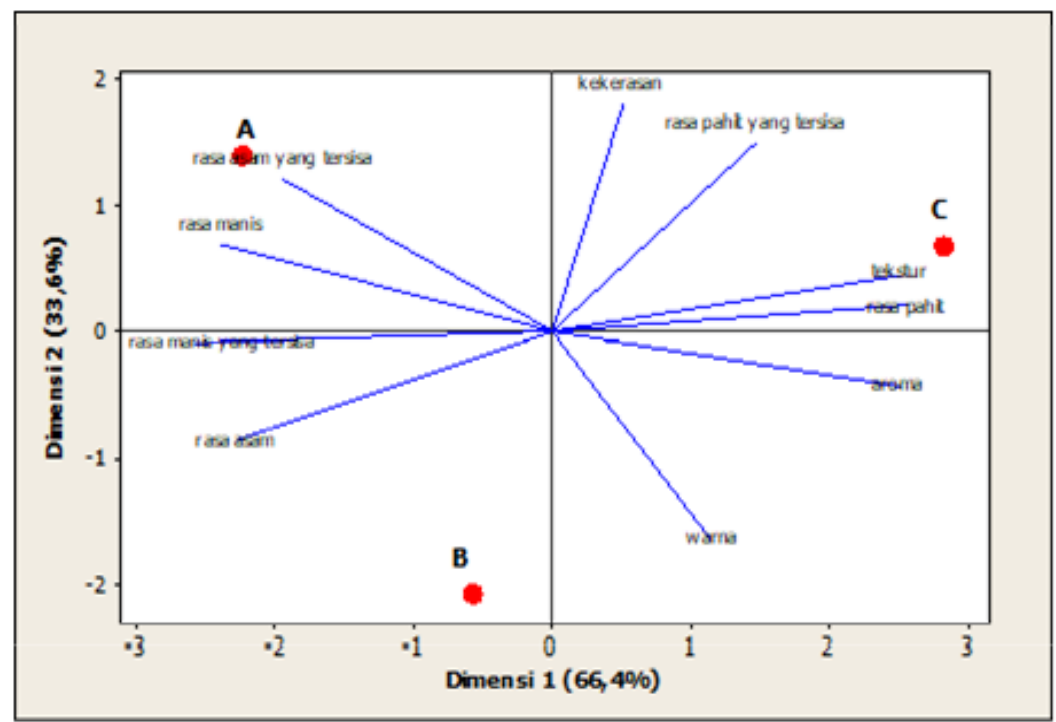

Gambar 5. Biplot antara produk multivitamin baru terhadap peubah atribut

\subsection{Analisis Biplot terhadap Tempat Tinggal Responden}

Keragaman yang diterangkan oleh sumbu 1 pada biplot ini sebesar $68.3 \%$ dan sumbu 2 sebesar $31.7 \%$ sehingga secara keseluruhan keragaman yang dapat dijelaskan oleh kedua sumbu tersebut sebesar $100 \%$. Nilai ini menunjukkan bahwa hasil yang diinterpretasikan oleh biplot ini sudah dapat menerangkan dengan sangat baik hubungan antara produk multivitamin baru terhadap tempat tinggal responden. Hasil biplot pada Gambar 6 menunjukkan bahwa responden yang bertempat tinggal di Bekasi dan Jakarta Timur memiliki tingkat keragaman tinggi. Hal ini dapat dilihat dari panjang vektor dari peubah tempat tinggal tersebut cenderung lebih panjang dibandingkan peubah tempat tinggal lainnya sehingga dapat diinterpretasikan bahwa penilaian responden yang bertempat tinggal pada ketiga tempat ini beragam antar ketiga produk multivitamin baru tersebut. Tingkat keragaman dapat diukur melalui simpangan baku. Nilai-nilai simpangan baku dari setiap tempat tinggal yang disajikan pada Tabel 4 memiliki perbedaan sangat kecil antar setiap tempat tinggal sehingga panjang vektor yang disajikan pada biplot memiliki panjang yang hampir sama pada setiap tempat tinggal.

Tabel 4 Simpangan Baku dari Setiap Peubah Tempat Tinggal

\begin{tabular}{ll}
\hline Tempat tinggal & Simpangan baku \\
\hline Jakarta Pusat & 0.235 \\
Jakarta Barat & 0.220 \\
Jakarta Timur & 0.320 \\
Jakarta Selatan & 0.272 \\
Jakarta Utara & 0.127 \\
Bogor & 0.096 \\
Depok & 0.235 \\
Tangerang & 0.083 \\
Bekasi & 0.333 \\
\hline
\end{tabular}


Responden yang bertempat tinggal di Jakarta Selatan memiliki penilaian tinggi terhadap produk A. Produk B diposisikan sebagai produk yang cenderung disukai oleh responden yang bertempat tinggal di Jakarta Barat, Jakarta Timur, Jakarta Pusat, Bogor, Tangerang, dan Bekasi. Produk C mendapatkan penilaian tertinggi oleh responden yang bertempat tinggal di Jakarta Utara dan Depok.

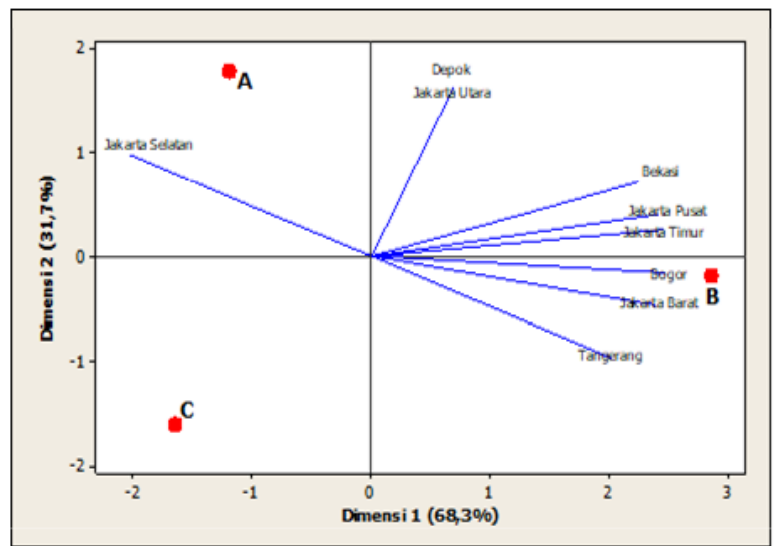

Gambar 6. Biplot antara produk multivitamin baru terhadap tempat tinggal responden

\subsection{Analisis Biplot terhadap Kelas Sosial Ekonomi (SEC) Responden}

Analisis biplot pada ketiga produk multivitamin baru terhadap kelas sosial ekonomi (SEC) responden ditampilkan pada Gambar 7 yang menghasilkan total keragaman $100 \%$ dengan $58.7 \%$ pada sumbu 1 dan $41.3 \%$ pada sumbu 2 . Hal ini menunjukkan bahwa interpretasi biplot yang dihasilkan sudah dapat menerangkan dengan baik hubungan antara produk multivitamin baru terhadap kelas sosial ekonomi (SEC) responden. Pada Gambar 7 terlihat bahwa panjang vektor dari peubah kelas sosial ekonomi (SEC) A2 cenderung lebih panjang dibandingkan peubah kelas sosial ekonomi (SEC) lainnya. Hal ini menunjukkan responden yang berada pada kelas sosial ekonomi (SEC) A2 memiliki tingkat keragaman tinggi sehingga dapat dikatakan bahwa penilaian responden yang berada pada kelas sosial ekonomi (SEC) A2 beragam antar ketiga produk multivitamin baru tersebut. Tingkat keragaman dapat diukur melalui simpangan baku. Nilai-nilai simpangan baku dari setiap kelas sosial ekonomi yang disajikan pada Tabel 5 memilki perbedaan sangat kecil antar setiap kelas sosial ekonomi (SEC) sehingga panjang vektor yang disajikan pada biplot memiliki panjang yang hampir sama pada setiap kelas sosial ekonomi (SEC).

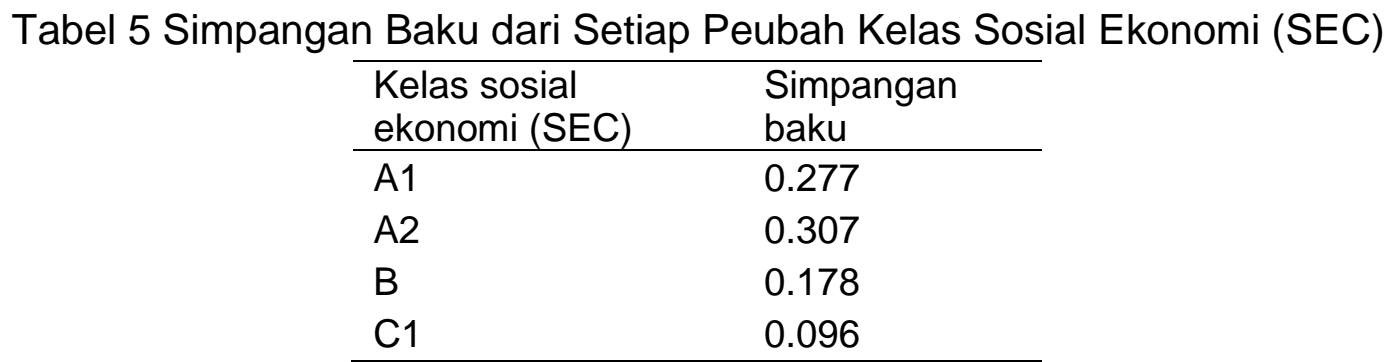

Nilai-nilai simpangan baku yang dihasilkan memiliki perbedaan sangat kecil antar setiap kelas sosial ekonomi (SEC) sehingga panjang vektor yang disajikan pada biplot memiliki panjang yang hampir sama pada setiap kelas sosial ekonomi (SEC). Hasil biplot pada Gambar 7 menunjukkan bahwa responden yang berada pada kelas sosial 
ekonomi (SEC) A2 dan C1 memiliki penilaian tinggi terhadap produk A. Produk B diposisikan sebagai produk yang cenderung disukai oleh responden yang berada pada kelas sosial ekonomi (SEC) B. Produk C merupakan produk yang dinilai tinggi oleh responden yang berada pada kelas sosial ekonomi (SEC) A1.

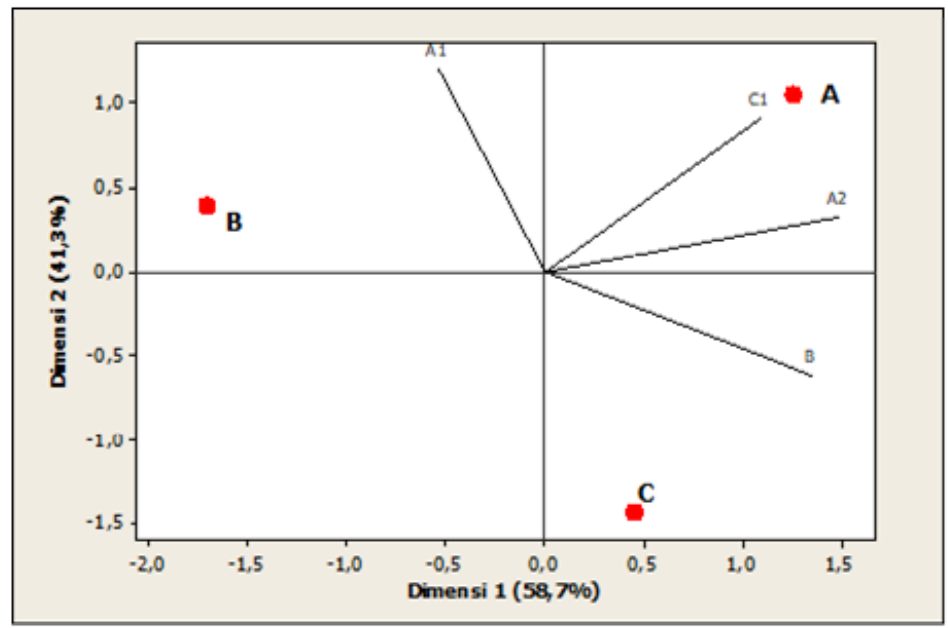

Gambar 7. Biplot antara produk multivitamin baru terhadap kelas sosial ekonomi (SEC) responden

\section{Simpulan}

Pada analisis ragam peubah ganda diperoleh antar ketiga jenis produk multivitamin baru memiliki perbedaan signifikan dengan taraf nyata $5 \%$ dari segi atribut organoleptik. Antar ketiga jenis produk multivitamin baru tersebut memiliki perbedaan signifikan pada penilaian aroma, rasa asam, dan rasa asam yang tersisa oleh responden, sedangkan pada atribut-atribut produk baru lainnya tidak memiliki perbedaan signifikan. Hasil analisis biplot menunjukkan bahwa produk A dipersepsikan oleh responden sebagai produk yang memiliki rasa yang terlalu manis serta yang tersisa di dalam mulut lebih asam dibandingkan produk lainnya. Produk ini cenderung disukai oleh responden yang bertempat tinggal di Jakarta Selatan serta responden yang berada pada kelas sosial ekonomi (SEC) A2 dan C1. Produk B dipersepsikan sebagai produk yang terlalu keras dengan memiliki sedikit rasa pahit yang tersisa di dalam mulut menurut responden. Produk ini dinilai tinggi oleh responden yang bertempat tinggal di Jakarta Barat, Jakarta Timur, Jakarta Pusat, Bogor, Tangerang, dan Bekasi serta responden yang berada pada kelas sosial ekonomi (SEC) B. Produk C dipersepsikan oleh responden sebagai produk yang memiliki aroma yang kuat dengan kehalusan tekstur relatif tinggi serta rasa yang lebih pahit dari produk lainnya. Produk ini cenderung disukai oleh responden yang bertempat tinggal di Jakarta Utara dan Depok serta berada pada kelas sosial ekonomi (SEC) A1. Secara keseluruhan, responden lebih menyukai produk $B$ dibandingkan kedua produk lainnya. Hal ini dikarenakan produk $\mathrm{B}$ cenderung populer di sebagian besar tempat tinggal responden.

\section{Daftar Pustaka}


Abdurrahman, R. (2011). Aplikasi biplot untuk identifikasi produk sabun mandi berdasarkan karakteristik demografi dan persepsi konsumen. Bogor (ID): Institut Pertanian Bogor.

Hays, W. (1976). Quantification in Psychology. New Delhi (IN): Prentice Hall. Jolliffe, I. (2002). Principal Component Analysis 2nd ed. New York (US): Springer.

Matjjik AA, S. I. (2011). Sidik Peubah Ganda dengan Menggunakan SAS. Bogor (ID): Departemen Statistika Institut Pertanian Bogor.

Rosiana NM, A. D. (2016). Karakteristik yogurt edamame hasil fermentasi kultul campuran bakteri asam laktat komersial sebagai pangan fungsional berbasis bijibijian. Jurnal Ilmiah Inovasi 1(2).

Sarwono J, B. H. (2014). Statistik Terapan: Aplikasi Untuk Riset Skripsi, Tesis, dan Disertasi Menggunakan SPSS, AMOS, dan Excel. Jakarta (ID): Elex Media Komputindo.

Walpole, R. (1995). Pengantar Statistika. Jakarta (ID): PT. Gramedia Utama.

Waryanto B, M. Y. (2006). Transformasi data skala ordinal ke interval menggunakan makro minitab. Jurnal Informatika Pertanian 15, Jurnal Informatika Pertanian.

Wijayanto H, Sugihartini N, S. M. S. F. (1998). Analisis pengembangan konsep produk menggunakan metode biplot. Forum Statistika dan Komputasi 3(1), 1-6. 